\title{
Elucidate the Renal Biochemical Factors in Patients with Malaria
}

\author{
Saira Baloch* and Xiaofang Pei \\ West China School of Public Health, No.4 West China Teaching Hospital, Sichuan University, Chengdu, Sichuan, China
}

*Corresponding author: Saira Baloch, Department of West China School of Public Health, No.4 West China, Teaching Hospital,

Sichuan University, Chengdu, Sichuan 610041, China

\section{ARTICLE INFO}

Received: 幽 November 19, 2019

Published: 㓞 December 09, 2019

Citation: Saira Baloch, Xiaofang Pei. Elucidate the Renal Biochemical Factors in Patients with Malaria. Biomed J Sci \& Tech Res 23(4)-2019. BJSTR. MS.ID.003943.

Keywords: Malaria; Urea; Creatinine; Microlab300

\section{ABSTRACT}

Purpose: The purpose of the present study is to elucidate the renal biochemical factors in patients with malaria and comparison with healthy control subjects. This study was conducted to compare the renal biochemical factors in patients with malaria and healthy controls. These patients were selected using simple random sampling technique.

Material \& Method: Eighty patients were diagnosed with malaria. Detailed history, general physical and systemic examination and necessary pathological, biochemical renal laboratory parameters and investigations were done. A sample of $5 \mathrm{ml}$ venous blood was drawn from each patient, centrifuged at $5000 \mathrm{rpm}$ for 20 minutes to separate the serum. The serum samples were analyzed for renal biochemical factors by using kit method on Microlab 300

Result: Among the 80 patients, 43 were males, and 37 were females. All patients were infected with malaria. All patients have increased serum creatinine and urea levels and urine output of fewer than $400 \mathrm{ml} /$ day were categorized as suffering from renal failure.

Conclusion: Patients infected with $P$. falciparum are at an increased risk of developing renal failure when compared to patients infected with other complications. Further research is necessary to understand the exact pathogenesis of various difficulties encountered in vivax malaria.

\section{Short Communication}

Malaria, a deadly parasitic disease, is a huge public health problem in sub-Saharan Africa, including Pakistan. An unhealthy environment can lead to mosquito breeding, and a poor diet can lead to risk factors such as weak immunity. 300 to 500 million clinical cases of malaria are registered every year, out of which $60 \%$ of the cases are registered in sub-Saharan Africa, furthermore, around $80 \%$ of malaria deaths also occur in sub-Saharan Africa. One million Africans die due to this deadly disease every year, most of them are children under five years [1]. It was reported that acute renal failure occurs in about $60 \%$ of all cases of complicated malaria [2,3]. Serum creatinine is generated from muscle metabolism and passes into the bloodstream and is usually excreted in urine. It is a molecule of the main consequence of manufacturing energy in muscles. About $2 \%$ of the body's creatine is converted to creatinine every day. However, creatinine is transported from the bloodstream to the kidneys. The kidneys filter out creatinine, and it disposes of urine. Because the muscle mass in the body is relatively constant from day to day, the level of creatinine in the blood remains unchanged. Hence, under certain pathological conditions, an elevated blood level of creatinine is observed indicating kidneys malfunction. It is usually a more accurate indicator of kidney function than urea [4]. In the present study, Microlab 300 was utilized to determine Urea and Creatinine levels from the serum of malarial patients as compared with the control subjects. 


\section{Material \& Methods}

This was a case-control study. In this study, blood samples of Malarial and Healthy control subjects were obtained from LUH, Jamsohoro, and City Hospital, Hyderabad, Sindh, Pakistan. A total of eighty patients with vivax malaria were recruited in this study, and eighty healthy control group, which was matched with age. To confirm the infection, the microscopic examination was also done and revealed the absence of Plasmodium vivax. These patients were selected using simple random sampling technique. A full medical and history were obtained, and physical examination was performed. A sample of $5 \mathrm{ml}$ venous blood was drawn from each patient, centrifuged at $5000 \mathrm{rpm}$ for 20 minutes to separate the serum. The serum samples were analyzed for urea and creatinine using the kit method on Microlab 300. The kit was obtained from Merck Company, Germany. All the chemicals and reagents obtained were of Analytical grade from Merck Company, Germany.

Ethical clearance for the study was obtained from the ethical committee of the LUMHS, Jamshoro.

\section{Method and Reaction for Tests with MICROLAB 300}

Determination of Urea: $1000 \mu \mathrm{L}$ of reagent sodium hydroxide (R1) followed by $200 \mu \mathrm{L}$ reagent picric acid (R2) in a $5 \mathrm{ml}$ sample tube containing ten $\mu \mathrm{L}$ blood serum were mixed and allowed to stand for 10 minutes to complete the reaction. The absorbance was measured at wavelength 500-546 nm which showed the relationship between the content of alkaline phosphates.

Determination of Creatinine: $400 \mu \mathrm{L}$ of reagent Sodium hydroxide (R1) followed by $100 \mu \mathrm{L}$ reagent Picric acid (R2) in a $5 \mathrm{ml}$ sample tube containing $50 \mu \mathrm{L}$ blood serum are mixed and were allowed to stand for 01 minutes to complete the reaction. The absorbance was measured at wavelength 500-546 nm which showed the relationship between the content of alkaline phosphatase and the absorbance of picric acid formation in a linear manner.

Statistical Analysis: Statistical assessment was done through the Statistical Package for Social Sciences (SPSS). The results are shown as Mean $\pm \mathrm{SD}$. The p-value $<0.05$ was considered as statistically significant.

\section{Result}

Total 80 Malaria positive cases were studied with Male and Female ratio of which had Plasmodium vivax infection. (Table 1). A clinical renal complication was as per Figure 1. Gender distribution was as per Figure 2 and patients' age ranged between 25 to 35 years shows in Figure 3. The results show an increased level of urea and creatinine in malarial patients as compared to the control subjects. Figure 1 shows an increased level of serum urea and creatinine in malarial patients as compared to the control subjects. Figures 2 \& 3 shows age and gender distribution in patients.
Table 1: Demographic Profile.

\begin{tabular}{|c|c|}
\hline Total No of patients & $\mathbf{8 0}$ \\
\hline Age group & $35--25$ \\
\hline Male: Female & Oct-70 \\
\hline
\end{tabular}

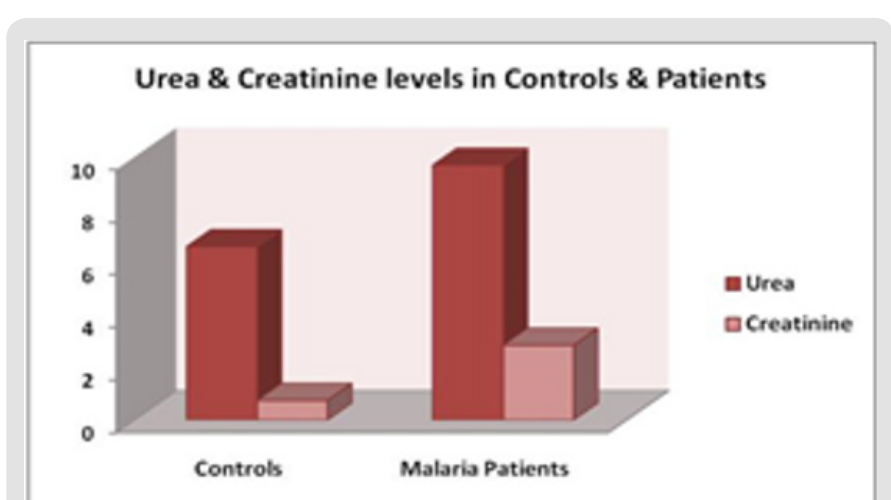

Figure 1: Increased Level of Urea and Serum Creatinine.

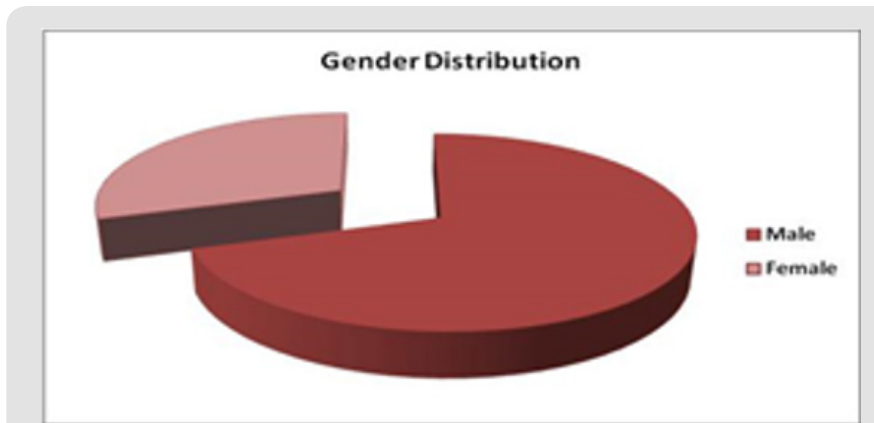

Figure 2: Gender distribution.

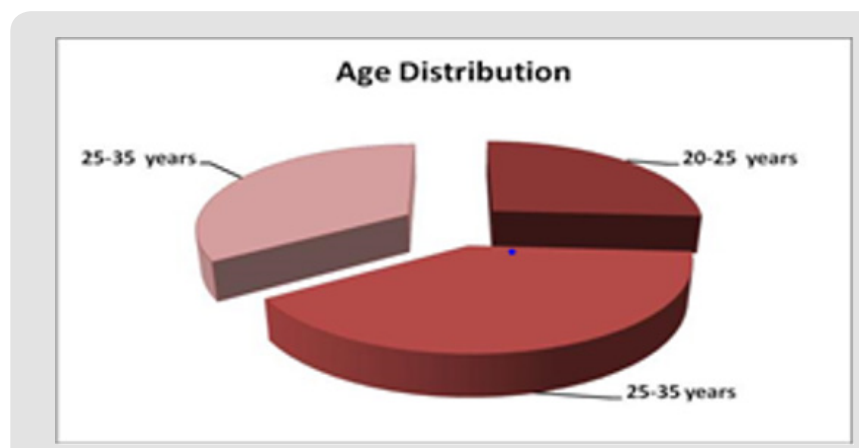

Figure 3: Age distribution.

\section{Discussion}

The history and chemical examinations results of the patients of confirmed vivax malaria and falciparum malaria shows the symptoms of fever and headache, Rigors chills, body aches in and vomiting, splenomegaly, pallor of all cases both in vivax and falciparum malaria. Additional symptoms including diarrhea less frequently, low blood pressure of 95/60 $\mathrm{mm}$ of $\mathrm{Hg}$, and a pulse of 120 beats/min were also seen in these patients. Specifically, the patients diagnosed with vivax malaria the symptoms with Jaundice, 
hepatosplenomegaly were admitted in the hospital in which the chemical examination shows decreased level of hemoglobin. It was reported that the high urea in malarial patients that vary considerably as the healthy controls could primarily be because of aspect alike further than malaria and the negative association amongst parasitemia and urea levels. Elevated and average levels of urea and creatinine are signs of insufficiency in renal function $[5,6]$. In the appearance of all these considerations, serum urea levels don't replicate the presentation of the renal such as creatinine as urea productivity similarly influences through dehydration, diet consumption, and tissue catabolism. Increases in urea levels in the patients recommend that the normal functioning of the kidneys [79]. In the current study, the $67 \%$ of patient had some form of renal involvement. In the same way, other studies have shown comparable results. Few studies have shown that falciparum malaria for $50 \%$ of renal damage and vivax malaria for $23 \%$ [10].

The percentage of renal involvement is higher in both infection groups. The hemodynamic changes are further malignant in falciparum malaria as the RBC parasitization rate, and microvascular obstruction is higher in falciparum malaria [11]. It was reported that the raised urea levels in patients with malaria which varied significantly from the control subjects the higher urea levels in malaria may be related to factors other than malaria, and there is no positive relationship between blood and urea levels in the parasite, with urea levels very different from those in the control group. Elevated creatinine levels are associated with the density of parasites. Serum creatinine and urea levels are usually adopted for the evaluation of renal sufficiency [12]. Above-average levels of serum creatinine and urea is a sign of kidney function deficiency $[13,14]$. In acute kidney failure, serum urea increases much faster than creatinine [15]. However, urea level does not indicate the renal function like creatinine does. Urea production could be influenced by drought, food consumption, and tissue metabolism. An increase in serum urea levels is associated with an increase in serotonin levels, indicating the natural function of the kidneys $[15,16]$. The Specific mechanism of diminishing of renal function in malaria is not well-known. Numerous hypotheses with the mechanical obstacle in infected erythrocytes, immune-mediated glomerular and tubular pathology, fluid loss because of several mechanisms and variations in the renal microcirculation were projected. The pathogenesis of renal contribution is probably mediated by immune complex deposition. A histopathological variation was observed in infected kidneys [16,17].

\section{Conclusion}

Patients infected with $P$. vivax and falciparum are at an increased risk of developing renal failure when compared to patients infected with other complications, as the early diagnosis will significantly reduce the mortality rate. Further studies are needed to understand the exact pathogenesis of various difficulties encountered in vivax malaria.

\section{Author Contribution}

Saira Baloch proposed the idea and wrote the paper; data analysis and proofreading the manuscript and done the final editing of the paper. Xiaofang Pei reviewed and improved the quality of the manuscript.

\section{Conflict of Interest}

No conflict of interest exits in the submission of this manuscript, and the manuscript has been approved by all authors for publication.

\section{References}

1. Snow RW, Guerra CA, Noor AM, Myint HY, Hay SI (2005) The global distribution of clinical episodes of Plasmodium falciparum malaria. Nature 434(7030): 214-217.

2. Boonpucknaviq V, Sitprija V (1979) Renal disease in acute Plasmodium falciparum infection in man. Kidney International 6: 44-56.

3. Nanda R, Mishra PK, Das UK, Rout SB, Mohapatra PC, et al. (2005) Evaluating the role of oxidative stress in determining the pathogenesis of falciparum malaria-induced acute renal failure. Indian Journal of Clinical Biochemistry 19(1): 93-96.

4. Gorsane I, Bourkhis L, Laatiri MA, Aloui S, Letaif A, et al. (2010) Insuffisance rénale aiguë révélatrice d'un lymphome rénal. À propos d'un casAcute renal failure caused by renal lymphoma. A case reports. Néphrologie \& Thérapeutique 6: 132-136.

5. Narayanan S, Appleton HD (1980) Creatinine. A Rev Clin Chem 26(8): $1119-1126$.

6. Wilairatana P, Westerlund EK, Aursudkij B, Vannaphan S, Krudsood S, et al. (1999) Treatment of malarial acute renal failure by hemodialysis. Am J Trop Med Hyg 60(2): 233-237.

7. Raphael C, Ogu GI (2010) Assessment of renal function of Nigerian children infected with Plasmodium falciparum. International Journal of Medicine and Medical Sciences 2(9): 251-255.

8. Liam-Ong S (2002) Current knowledge in falciparum malaria-induced acute renal failure. J Med Assoc Thai p. S16-24.

9. Yemura SA, Luo S, Moreno SN, Docampo R (2000) Oxidative phosphorylation, $\mathrm{Ca}\left(2^{+}\right)$transport, and fatty acid-induced uncoupling in malaria parasites mitochondria. J Biol Chem 275: 9709 -9715.

10. Cox Singh J, Davis TME, Lee KS, Shamsul SSG, Matusop A, et al. (2008). Plasmodium knowlesi malaria in humans is widely distributed and potentially life-threatening. Clin Infect Dis 46(2): 165-171.

11. Nguansangiam S, Day NP, Hien TT, Mai NT, Chaisri U, et al. (2007) A quantitative ultrastructural study of renal pathology in fatal Plasmodium falciparum malaria. Trop Med Int Health 12(9): 1037-1050.

12. Smith GL, Shlipak MG, Havranek EP, Foody JM, Masoudi FA, et al. (2006) Serum urea nitrogen, creatinine and estimators of renal function. Arch. Int. Med 166(10): 1134-1142.

13. Narayanan S, Appleton HD (1980) Creatinine. A Rev Clin Chem 26(8): 1119-1126.

14. Whelton A, Watson AJ, Rock RC, (1994) In Tietz textbook of clinical chemistry, CA burtis and ER Ashwood, (Eds.)., WB Saunders Company, London, UK, pp. 1528.

15. Emian Ong S (2002) Current knowledge of falciparum malaria-induced acute renal failure. JMed Assoc Thai Suppl 16: 24.

16. Das BS (2008) Renal failure in malaria: A Rev J Vector Borne Dis 45(2): 83-97.

17. Barsoum RS (2000) Malarial acute renal failure. J. Am. Soc. Nephrol 11(11): 2147-2154 
ISSN: 2574-1241

DOI: $10.26717 /$ BJSTR.2019.23.003943

Saira Baloch. Biomed J Sci \& Tech Res

(c) (P) This work is licensed under Creative

Submission Link: https://biomedres.us/submit-manuscript.php

$\begin{array}{ll}\text { BIOMEDICAL } & \text { Assets of Publishing with us } \\ \text { RESEARCHES } & \text { Global archiving of articles } \\ & \text { - Immediate, unrestricted online access } \\ & \text { - Rigorous Peer Review Process } \\ \end{array}$

